\title{
Aplikasi Penentuan Jalur Evakuasi dan Lokasi Bencana Tanah Longsor di Kabupaten Bogor Berbasis Web
}

\author{
Ayres Pradiptyas, Marcalle no Reza Saputra, Iklima Ermis Is mail \\ Program Studi Teknik Informatika \\ Politeknik Negeri Jakarta \\ Indonesia \\ ayres.pradiptyas@tik.pnj.ac.id, marcallenoreza@gmail.com, iklimaermis.is mail@tik.pnj.ac.id
}

Diterima: 18 Oktober 2018. Disetujui 25 Oktober 2018. Dipublikasikan Nopember 2018

\begin{abstract}
Abstrak - Provinsi Jawa Barat termasuk ke dalam provinsi dengan jumlah penduduk terbanyak di Indonesia. Kabupaten Bogor sebagian besar wilayahnya berbukit dan bergunung serta memiliki curah hujan tinggi dan kontur tanah di daerah ini tersusun oleh material tanah yang tidak padat, dan pergerakan tanah yang cukup tinggi dikarenakan curah hujan sehingga Kabupaten Bogor merupakan salah satu daerah di Jawa Barat yang berpotensi mengalami bencana tanah longsor. Oleh sebab itu, untuk menghindari jatuhnya korban yang lebih banyak diperlukan upaya agar dapat meminimalisir akibat yang ditimbulkan maka pentingnya dibuat aplikasi yang dapat membantu masyarakat di Kabu paten Bogor untuk mendapatkan informasi mengenai jalur evakuasi bencana tanah longsor serta informasi tentang lokasi bencana tanah longsor. Aplikasi dibuat berbasis web sehingga dapat diakses oleh semua orang. Google Maps API yang terdapat di dalam web digunakan untuk menampilkan titik lokasi rawan dan titik lokasi aman bencana tanah longsor serta dibangun dengan teknologi geo-location menggunakan metode Guidelines for Rapid Application Engineering (GRAPPLE). Dalam skripsi ini akan dibangun aplikasi berbasis web untuk mengetahui titik lokasi rawan tanah longsor, status aman atau tidak aman serta mendapatkan jalur evakuasi dari bencana tanah longsor.
\end{abstract}

Kata kunci : Geo-Location, Google Maps, GRAPPLE, Kabupaten Bogor, Tanah Longsor, Web

\section{PENDAHULUAN}

Indonesia merupakan negara kepulauan sehingga memiliki risiko bencana alam yang cukup tinggi. Dapat dilihat bahwa dalam beberapa tahun terakhir di Indonesia sering terjadi bencana alam. Berbagai bencana alam mulai dari gempa bumi, tsunami, letusan gunung berapi, banjir, tanah longsor, kekeringan, dan kebakaran hutan adalah contoh bencana alam yang sering terjadi di Indonesia. Tentu saja hal tersebut akan memberikan dampak bagi orang-orang yang mengalaminya.

Provinsi Jawa Barat termasuk ke dalam provinsi dengan jumlah penduduk terbanyak di Indonesia. Kabupaten Bogor merupakan salah satu daerah di Jawa Barat yang berpotensi mengalami tanah longsor. Menurut Badan Penangulangan Bencana Nasional daerah Kabupaten Bogor termasuk ke dalam peringkat lima nasional sebagai daerah rawan longsor karena dari 40 kecamatan yang ada di Kabupaten Bogor, 27 kecamatan termasuk rawan tanah longsor. Faktor utamanya ialah kontur tanah di daerah ini tersusun oleh material tanah yang tidak padat, dan pergerakan tanah yang cukup tinggi dikarenakan curah hujan.

Dilihat dari aspek demografi, Kabupaten Bogor termasuk kawasan padat penduduk dan umumnya pemukiman tersebut terletak pada lereng perbukitan. Oleh sebab itu, untuk mengurangi jatuhnya korban diperlukan upaya agar dapat meminimalkan akibat yang ditimbulkan. Upayaupaya tersebut perlu dilakukan mengingat kejadian tanah longsor mengakibatkan kerugian material dan korban jiwa yang tidak sedikit, terutama di wilayah yang padat penduduknya.

Untuk dapat memberitahu masyarakat mengenai bencana tanah longsor diperlukan adanya suatu sistem yang dapat memberikan peringatan kepada masyarakat di Kabupaten Bogor dengan menampilkan pemetaan titik lokasi rawan tanah longsor, memberikan informasi mengenai posisi aman atau tidak amannya lokasi mereka saat ini dan memberitahu informasi jalur evakuasi terdekat dari tempat mereka berada. Aplikasi ini merupakan salah satu bentuk kegiatan mitigasi bencana tanah longsor dan secara umum dapat dijadikan panduan bagi 
masyarakat untuk mengantisipasi terjadinya tanah longsor di wilayah Kabupaten Bogor.

\section{TINJAUAN PUS TAKA}

\section{A. Pengertian Tanah Longsor}

Menurut Nandi (2007), tanah longsor secara umum adalah perpindahan material pembentuk lereng berupa batuan, bahan rombakan, tanah, atau material laoporan, bergerak kebawah atau keluar lereng. Secara geologi tanah longsor adalah suatu peristiwa geologi dimana terjadi pergerakan tanah seperti jatuhnya bebatuan atau gumpalan besar tanah. Gejala umum tanah longsor ditandai dengan munculnya retakan-retakan dilereng yang sejajar dengan arah tebing, biasanya terjadi setelah hujan, munculnya mata air baru secara tiba-tiba dan tebing rapuh serta kerikil mu lai berjatuhan.

\section{B. Pengertian Kabupaten Bogor}

Kabupaten Bogor adalah sebuah kabupaten di provinsi Jawa Barat, Indonesia. Kabupaten Bogor terdiri atas 40 kecamatan, yang dibagi atas sejumlah desa dan kelurahan. Pusat pemerintahan Kabupaten Bogor terletak di Kecamatan Cibinong. Menurut klasifikasi Schmidt-Ferguson, iklim di Kabupaten Bogor termasuk tropis tipe A (sangat basah) berada di wilayah selatan dan tipe B (basah) berada di wilayah utara. Suhu udara wilayah selatan Kabupaten Bogor berkisar $20-30^{\circ} \mathrm{C}$ serta memiliki hawa yang sejuk, sedangkan untuk wilayah utara Kabupaten Bogor memiliki hawa yang panas dengan curah hujan tahunan berkisar 2.500-5.000 $\mathrm{mm} /$ tahun.

\section{Pengertian Web}

Web atau aplikasi berbasis Web (Web-based application) menurut Janner Simarmata (2010:47) adalah aplikasi yang dijalankan melalui browser. Aplikasi seperti ini pertama kali dibangun hanya dengan mengunakan bahasa yang disebut HTML (HyperText Markup Language) dan protokol yang digunakan dinamakan HTTP (HyperText Transfer Protocol).

\section{Pengertian Google Maps API}

Menurut Gibson \& Erle (2006), Google Maps adalah sebuah penyedia layanan pemetaan dan kartografi berbasis web yang disediakan oleh Google. Google Maps memiliki waktu loading yang relatif cepat. Peta pada Google Maps ditampilkan secara tiled map. Google Maps menawarkan fasilitas peta dan gambar satelit untuk seluruh dunia dan baru- baru ini memiliki fitur untuk mencari rute terpendek dari te mpat-te mpat tertentu.

\section{E. Pengertian Guideliness for Rapid Application Engineering (GRAPPLE)}

Menurut Schmuller (2004), GRAPPLE merupakan sebuah pemodelan proses dalam pengembangan software yang menekankan pada aksi-aksi yang dilakukan pada sejumlah tahapan, setiap tahap akan menghasilkan produk kerja dengan bentuk yang berorientasi objek. Berikut merupakan tahapan- tahapan pada metode GRAPPLE: :

\section{- Requirements Gathering}

Tahap ini melakukan analisis terhadap masalah, fungsi dan komponen produk yang akan dibuat (system requirements). Tahap ini penting, karena tahap lain tidak dapat dibuat sesuai dengan yang diinginkan jika tidak memahami produk yang akan dibuat.

\section{Analysis}

Tahap pengembangan model dari data dan informasi yang diperoleh dari requirements gathering. Model merupakan bentuk transisi dari informasi dasar kedalam bentuk model dan diagram.

- Design

Merupakan tahap implementasi dan perancangan dari model serta diagram yang telah dianalisis. Dalam tahap ini akan dikembangkan sejumlah objek diagram dengan fungsi, interaksi dan operasi tertentu. Diagram-diagram tersebut antara lain akan menunjukkan proses dan aktifitas pada sistem, rancangan data dan penyimpanan data, serta rancangan antarmuka.

- Development

Merupakan tahap penerapan model dan diagram yang telah terbentuk, antara lain dengan melakukan pengembangan source code, pengecekan dan test code, serta pembuatan User Interface.

- Deployment

Merupakan tahap terakhir yang dilakukan setelah development. Sistem yang terbentuk akan integrasikan dengan hardware maupun dengan sistem operasi yang digunakan.

\section{METODOLOGI}

Metodologi yang digunakan dalam Aplikasi Penentuan Jalur Evakuasi Dan Lokasi Bencana Tanah Longsor Di Kabupaten Bogor Berbasis Web adalah GRAPPLE (Guidelines for Rapid Application 
Engineering). GRAPPLE merupakan sebuah pemodelan proses dalam pengembangan software yang menekankan pada aksi-aksi yang dilakukan pada sejumlah tahapan, setiap tahap akan menghasilkan produk kerja dengan bentuk yang berorientasi objek (Schmuller, 2004). Dalam GRAPPLE, tahapan dapat disusun dalam bentuk yang tidak statis, sehingga setiap tahap dapat dikerjakan dengan urutan kerja yang tidak harus sesuai dengan urutan yang ada. Tahapan yang digunakan dalam GRAPPLE mencakup analisis kebutuhan sistem, pengembangan model dan diagram, pembuatan kode sampai tahap instalasi dan evaluasi.

Tahapan pertama adalah Requirement Gathering. Tahap ini melakukan analisis terhadap masalah, fungsi dan komponen produk yang akan dibuat (system requirements). Tahap ini penting, karena tahap lain tidak dapat dibuat sesuai dengan yang diinginkan jika tidak memahami produk yang akan dibuat. Pada aplikasi ini kami melakukan interview dan meminta data tentang bencana tanah longsor yang dimiliki oleh Badan Penanggulangan Bencana Daerah (BPBD) Kabupatan Bogor. Lalu data dan informasi yang diperoleh tersebut dianalisa dan ubah ke bentuk model dan diagram. Kemudian tahan selanjutnya yaitu design. Di tahap ini akan dibuat diagram-diagram UML dan tampilan antar muka untuk aplikasi tanah longsor. Selanjutnya adalah tahap Development, pada tahap ini diagram UML dan rancangan antarmuka akan diubah menjadi source code aplikasi, pengecekan dan test code. Setelah aplikasi selesai, tahap terakhir adalah Deployment yaitu mengintegrasikan dan mengimplementasi aplikasi dengan hardware dan sistem operasi yang digunakan.

A. Tujuan dan Manfaat Aplikasi Tanah Longsor Adapun tujuan dari aplikasi ini adalah dapat memetakan lokasi rawan bencana tanah longsor serta dapat memberikan peringatan status aman maupun tidak aman kepada pengguna di wilayah Kabupaten Bogor. Adapun manfaat dari aplikasi ini yaitu mengedukasi masyarakat tentang cara penanggulangan bencana untuk mengurangi korban jiwa yang ditimbulkan dan memberitahu jalur evakuasi tanah longsor di sekitar lokasi bencana.

\section{ANALIS IS DAN PERENCANAAN S ISTEM}

A. Deskripsi Program Aplikasi

Aplikasi Penentuan Jalur Evakuasi dan Lokasi

Bencana Tanah Longsor merupakan aplikasi yang berfungsi memetakan titik lokasi rawan longsor dan memberikan informasi jalur evakuasi dari lokasi rawan tanah longsor menggunakan geo-location pada wilayah Kabupaten Bogor. Aplikasi ini dapat diakses melalui web dengan tujuan agar dapat digunakan secara luas oleh semua orang. Dengan adanya aplikasi ini, pengguna dapat mengetahui apakah lokasi mereka saat ini aman dari lokasi rawan tanah longsor dan memberikan jalur aman menuju tempat evakuasi dari lokasi bencana tanah longsor dengan bantuan geo-location.

\section{B. Pemodelan Sistem \\ 1) Use case diagram \\ a) Use case dan Aktor}

Untuk menjelaskan use case dan aktor yang terkait dengan sistem ini, dipertimbangkan peran dan fungsi yang telah diuraikan di atas. Berikut use case diagram untuk Aplikasi Penentuan Jalur Evakuasi dan Lokasi Bencana Tanah Longsor.

- User merupakan aktor yang bertindak sebagai pengguna pada Aplikasi Penentuan Jalur Evakuasi dan Lokasi Bencana Tanah Longsor dan memiliki hak akses terhadap fitur-fitur yang terdapat pada aplikasi jalur evakuasi dan lokasi tanah longs or berbasis web.

- Pada aplikasi Penentuan Jalur Evakuasi dan Lokasi Bencana Tanah Longsor berbas is web ini hanya terdapat satu aktor yang terlibat yaitu user yang memiliki hak akses untuk melakukan aktivitas terhadap fitur-fitur yang terdapat pada aplikasi.

b) Diagram Use case

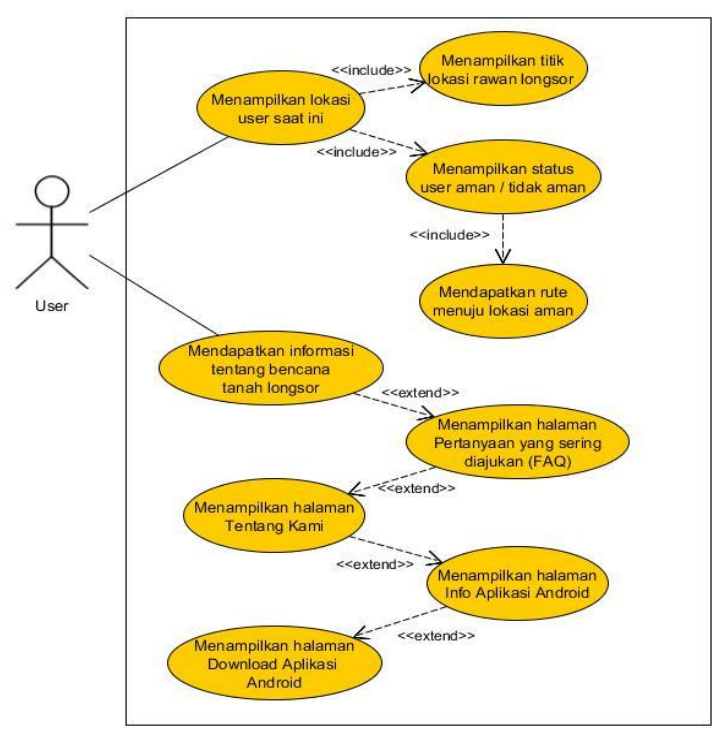

Gambar 1 Diagram Use Case Sistem 


\section{2) Diagram Aktifitas}

Activity diagram adalah teknik untuk menggambarkan logika prosedural, proses bisnis, dan alur kerja. Activity diagram memainkan peran yang mirip dengan flowchart, tetapi perbedaan utama dari activity diagram adalah menyediakan sebuah mekanis me untuk menggambarkan kegiatan yang tampak secara paralel.

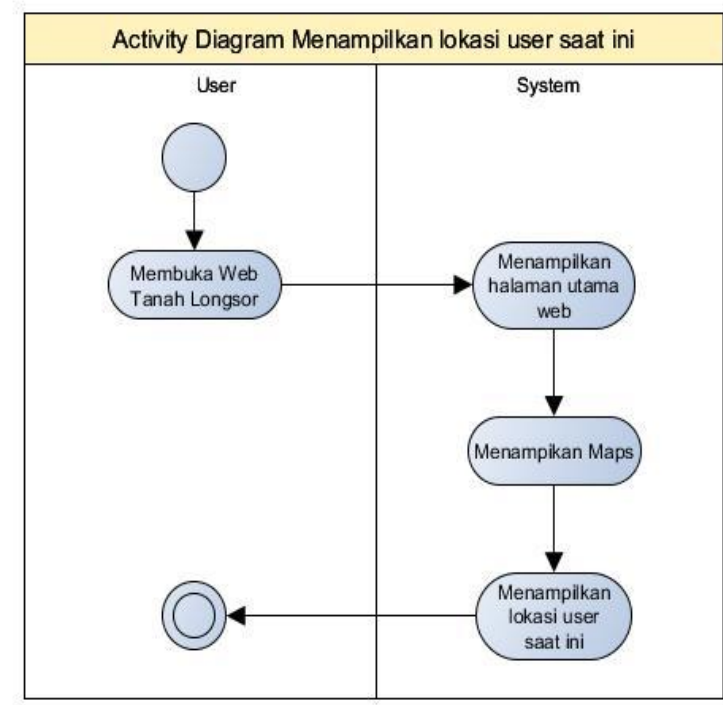

Gambar 2 Diagram aktifitas menampilkan lokasi user saat ini.

\section{3) Diagram Sequence}

Diagram Sequence menjelaskan interaksi objek yang disusun berdasarkan urutan waktu. Secara mudahnya sequence diagram adalah gambaran tahap demi tahap, termasuk kronologi (urutan) perubahan secara logis yang seharusnya dilakukan untuk menghasilkan sesuatu sesuai dengan use case diagram. Diagram ini juga menunjukkan serangkaian pesan yang dipertukarkan oleh obyek-obyek yang melakukan suatu tugas atau aksi tertentu. Contoh diagram sequence pada aplikasi ini adalah sebagai berikut.

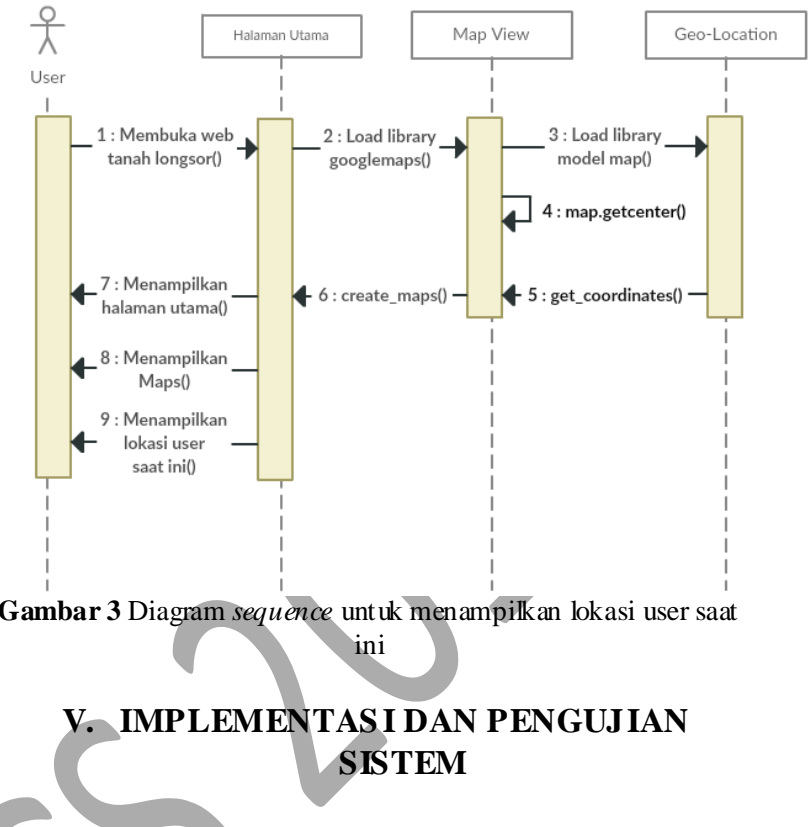

Pada tahapan ini akan dilakukan implementasi rancangan ERD (Entity Relationship Diagram) yang telah dibuat sebelumnya ke dalam bentuk basis data dan antarmuka program aplikasi penentuan jalur evakuasi dan lokasi bencana tanah longsor.

\section{A. Halaman Utama}

Pada halaman tersebut terdapat tombol untuk mengakses seluruh halaman web yang ada pada aplikasi penentuan jalur evakuasi dan lokasi bencana tanah longsor. Fitur seperti Get Location dan Get Status berada pada halaman utama. Pemetaan titik lokasi tanah longsor akan muncul pada halaman utama web aplikasi penentuan jalur evakuasi dan lokasi bencana tanah longsor. Seluruh aktivitas yang berkaitan dengan pemetaan akan terfokus pada area ini. Pada gambar di atas dapat dilihat bahwa titik marker dan radius lingkaran berwarna merah yang berarti daerah tersebut rawan bencana tanah longsor.

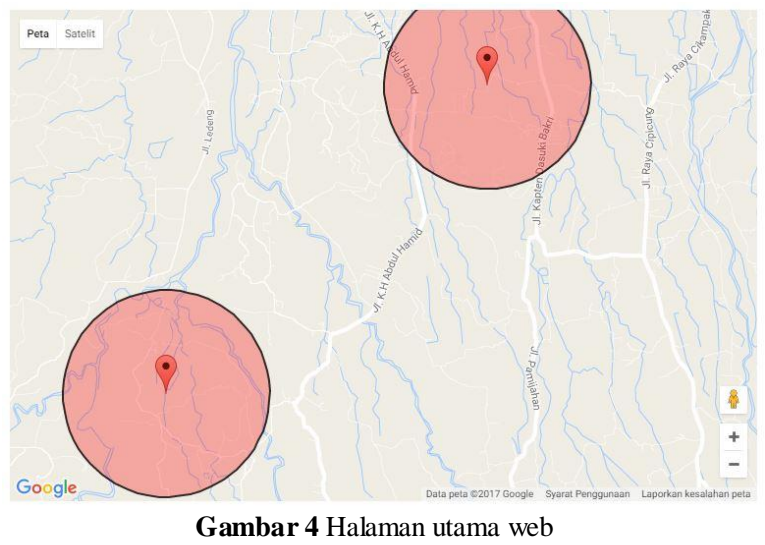




\section{B. Halaman Informasi Bencana}

Pada halaman ini pengguna dapat melihat informasi tentang bencana tanah longsor, tips dan trik menghadapi bencana tanah longsor, cara-cara penangulanggan tanah longsor, mitigasi dan hal yang berkaitan dengan tanah longsor. Adanya halaman ini memudahkan petugas Badan Penanggulangan Bencana Daerah (BPBD) untuk mengedukasi masyarakat di Kabupaten Bogor.

Informasi Tentang Bencana Tanah Longsor

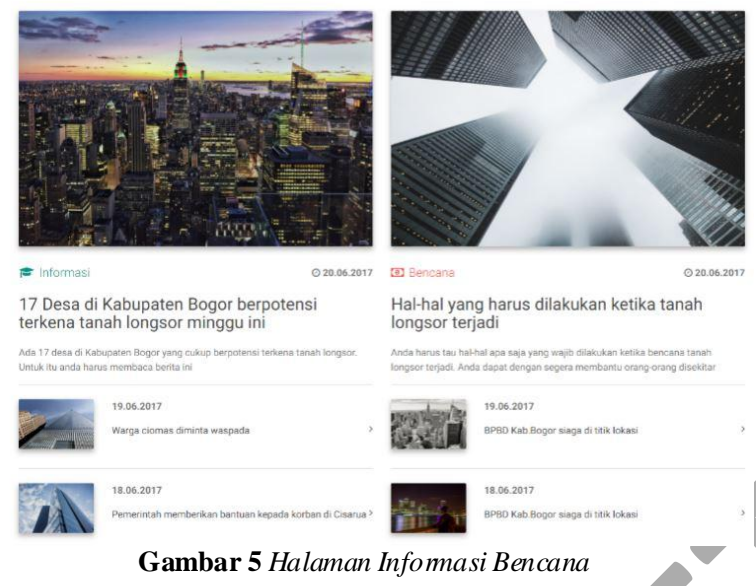

\section{Halaman Info Aplikasi Android}

Halaman ini merupakan halaman yang berisi tentang informasi aplikasi penentuan jalur evakuasi dan lokasi bencana tanah longsor di Kabupaten Bogor berbasis android. Pengguna dapat melihat fitur apa saja yang terdapat pada aplikasi versi mobile.

\section{Info Aplikasi Android}

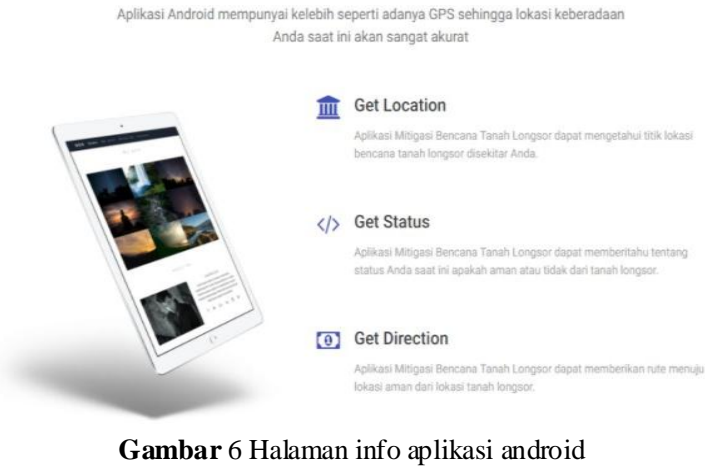

\section{Halaman Download Aplikasi Android}

Pada halaman ini, pengguna dapat memperoleh aplikasi versi android melalui link download yang telah disediakan. Pengguna dapat memilih 3 file hosting dari aplikasi tanah longsor berbasis android.

\section{Download Aplikasi Tanah Longsor berbasis Android}

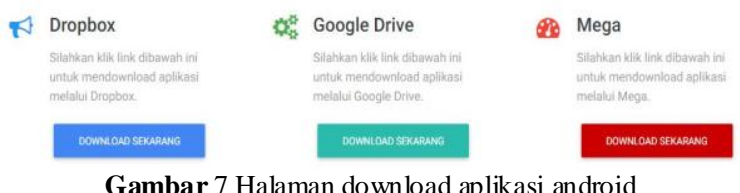

Gambar 7 Halaman download aplikasi android

\section{KES IMPULAN}

Berdasarkan hasil analisa, perancangan, dan implementasi yang sudah dilakukan sebelumnya, penulis mengambil kesimpulan sebagai berikut:

1. Aplikasi telah dibuat ke dalam bentuk web sehingga dapat dengan mudah memberikan informasi status aman, titik lokasi rawan longsor dan rute aman (jalur evakuasi) kepada pengguna di Kabupaten Bogor

2. Aplikasi ini memiliki 3 fitur utama, yaitu Get Location yang berfungsi untuk me mberitahu titik lokasi rawan tanah longsor di wilayah Kabupaten Bogor. Selanjutnya Get Status yang berfungsi untuk memberikan informasi apakah lokasi pengguna saat ini aman atau tidak aman dari lokasi tanah longsor. Fitur ini dapat bekerja setelah mengakses fitur Get Location. Fitur terakhir yaitu Get Direction yang berfungsi memberikan jalur evakuasi menuju lokasi aman dari tanah longsor.

3. Aplikasi ini dibuat dan dikembangkan menggunakan teknologi Geo-Location dengan memanfaatkan API dari Google Maps yang dapat digunakan untuk kebutuhan dalam pembuatan peta di web.

\section{REFERENS I}

[1] Zahir Zainuddin, Ahyar Muawwal, Suryani, Merna Baharuddin. 2015. Online Mobile Mapping Application Development For Monitoring Fruit Tree Plantation. Asian Research Publishing Network (ARPN) Journal of Engineering and Applied Sciences. Indonesia.

[2] Shunfu Hu, Ting Dai. 2013. Online Map Application Development Using Google Maps API, SQL Database, and ASP.NET. International Journal of Information and Communication Technology Research. United States.

[3] Kadibagil Mahesh, Dr. H S Guruprasad. 2014. Position Detection and Tracking System. International Journal of Computer Science and Information Technology \& Security (IJCSIT S). India.

[4] Harpinder Singh, Karamjeet Singh, Rajneesh Kumar. 2012. Emergency Response Planning for Road Accidents in Ludhiana District using Google Maps. International Journal of Computer Science and Technology (IJCST). India. 
[5] Arief Hidayat, Victor Gayuh Utomo. 2014. Implementing Code Igniter Framework in Open Source Mobile Leaming Application. International Journal of Computer Applications. Indonesia.

[6] Dr. Khalifa A. Salim, Ibrahim Mohammed Idrees. 2013. Design and Implementation of Web-Based GPS-GPRS Vehicle Tracking System. International Journal of Computer Science Engineering and Technology (IJCSET). Iraq.

[7] Mihir Garude, Nirmal Haldikar. 2014. Real Time Position Tracking System Using Google Maps API V3. International Journal of Scientific and Research Publications. India

[8] Wiwin Windihastuty, Muhammad Irsan. 2017. Explorers Zoo: An Application Model of Global Positioning System A Case Study in Ragunan Zoo. International Conference on Information andEducation Technology. Jepang.

[9] Agus Aan Jiwa Permana, Putu Perdana Kusuma Wiguna. 2012. Tanah Longsor : Memperkecil Resiko Bencana Menggunakan Sistem Informasi Geografis (Studi Kasus: Kecamatan Kokap, Kulon Progo, DIY). Jurnal Pendidikan Teknologi dan Kejuruan. Indonesia.

[10] Indra Rozi, Asrul Huda, Oktoria. 2015. Sistem Informasi Peta Digital Lokasi Kos di Kota Padang Menggunakan Google Map API VB berbasis Framework Codeigniter. Jurnal Vokasional Teknik Elektronika \& Informatika. Indonesia. 